\title{
Fuzzy TOPSIS for Multiresponse Quality Problems in Wafer Fabrication Processes
}

\author{
Chiun-Ming Liu, Mei-Yu Ji, and Wen-Chieh Chuang \\ Department of Industrial Engineering and Systems Management, Feng Chia University, Taichung 407, Taiwan
}

Correspondence should be addressed to Chiun-Ming Liu; cmliu@fcu.edu.tw

Received 25 January 2013; Accepted 31 March 2013

Academic Editor: Yongming Li

Copyright ( 2013 Chiun-Ming Liu et al. This is an open access article distributed under the Creative Commons Attribution License, which permits unrestricted use, distribution, and reproduction in any medium, provided the original work is properly cited.

\begin{abstract}
The quality characteristics in the wafer fabrication process are diverse, variable, and fuzzy in nature. How to effectively deal with multiresponse quality problems in the wafer fabrication process is a challenging task. In this study, the fuzzy technique for order preference by similarity to an ideal solution (TOPSIS), one of the fuzzy multiattribute decision-analysis (MADA) methods, is proposed to investigate the fuzzy multiresponse quality problem in integrated-circuit (IC) wafer fabrication process. The fuzzy TOPSIS is one of the effective fuzzy MADA methods for dealing with decision-making problems under uncertain environments. First, a fuzzy TOPSIS methodology is developed by considering the ambiguity between quality characteristics. Then, a detailed procedure for the developed fuzzy TOPSIS approach is presented to show how the fuzzy wafer fabrication quality problems can be solved. Real-world data is collected from an IC semiconductor company and the developed fuzzy TOPSIS approach is applied to find an optimal combination of parameters. Results of this study show that the developed approach provides a satisfactory solution to the wafer fabrication multiresponse problem. This developed approach can be also applied to other industries for investigating multiple quality characteristics problems.
\end{abstract}

\section{Introduction}

Wafer fabrication process plays an important role in the quality of integrated-circuit (IC) semiconductor components. The quality characteristics of IC semiconductor components are diverse, variable, and fuzzy in nature. The design and development of wafer fabrication process should take many aspects into consideration as it takes so much time and cost to solve the quality problem. How to effectively deal with the multiresponse quality problems in the wafer fabrication process is important and challenging.

Taguchi method, design of experiments, or response surface method have been helpful and prevailing in the industry for finding good combinations of parameters for manufacturing processes [1]. Traditionally, most such applications are for solving single-response quality problems and reducing quality loss and variance. As the demand for a product with higher quality is increasing, the requirements for product quality characteristics tend to be multidimensional. Also, the environment under the various quality measurements is becoming uncertain and fuzzy. Hence, it is essential to develop more appropriate methods for solving the fuzzy multiresponse quality problem.

Several analytical methods have been proposed for dealing with the multiresponse quality problem. In the early years, the weighted method, regression analysis, desirability function, or loss function were used to simplify the multiresponse problem as a single-response problem with limited results [2-5]. Recently, more sophisticated methods such as weighted allocation method, regression and mathematical programming technique, principal components analysis, data envelopment analysis, neural network, and grey relational analysis have been applied to the multiresponse problem with satisfactory results [6-14]. However, for the multiresponse quality problem under fuzzy environments, there remain several issues that need to be further investigated.

Multiattribute decision analysis (MADA) methods deal with decision problems with known alternatives and have been applied in assessment and evaluation problems, such as assessment of design quality [15], evaluation of production 
processes [16], and appraisal of software packages [17]. When the attributes, outcomes, or preferences of alternatives cannot be certain or crisp under fuzzy environments, such decision problems can be fuzzy in nature qualitatively and quantitatively. Those fuzzy MADA problems need the use of fuzzy set theory and related soft computing techniques for resolution.

There are several methods that can be used for solving MADA problems, such as simple additive weight, technique for order preference by similarity to ideal solution (TOPSIS), elimination et choice translating reality (ELECTRE), analytic hierarchy process (AHP), weighted product, median ranking, linear assignment, and hierarchical additive weighting [18]. Among those methods, the TOPSIS method exhibits several features, such as flexibility, robust, and stability, that can be applied to deal with the fuzzy multiresponse quality problems. In this study, the fuzzy TOPSIS is proposed to investigate the multiresponse quality problems in wafer fabrication process. The motivation is that the fuzzy TOPSIS method can take advantage of normalizing and defuzzifying fuzzy data collected from multiresponse quality problems and can utilize fuzzy entropy measures to provide objective weights for each criterion [19]. Furthermore, the fuzzy TOPSIS method can be integrated with Taguchi method to develop an exact procedure for obtaining satisfactory combinations of parameters.

The objectives of this study are threefold. First, a fuzzy TOPSIS method with fuzzy entropy weight measure is developed for the fuzzy multiresponse quality problem. Second, Taguchi method is combined with the developed fuzzy TOPSIS method to select satisfactory combinations of parameters for wafer fabrication process. Finally, the developed approach is implemented to show the benefits of improving the quality problem in wafer fabrication process.

\section{Development of Fuzzy TOPSIS Method}

The method of technique for order preference by similarity to an ideal solution (TOPSIS) was proposed by [18] in which the concept of compromise solution [20] is adopted and served as proximity to the ideal solution. The TOPSIS method selects the best alternatives based on criteria in which the distance to the positive ideal solution is the shortest and the distance to the negative ideal solution is the longest. The positive ideal solution is the one with the maximal benefit value and minimal cost value among all possible alternatives. The negative ideal solution is the one with minimal benefit value and maximal cost values. The positive and negative ideal solutions can be found by way of weighting the normalized decision matrix. A relative closeness is computed and used for ranking all possible alternatives by the measure of Euclidean distance.

The fuzzy TOPSIS method is one of the fuzzy MADA methods in which the fuzzy set theory is used to modify the TOPSIS method for decision problems under fuzzy environments. Fuzzy set theory is applied to provide fuzzy number for describing any fuzzy subset of responses and preferences with suitable membership functions. Then, the developed fuzzy TOPSIS method is applied to rank all possible alternatives by the criteria of relative closeness to positive and negative ideal solutions. The following is the detailed procedure for the developed fuzzy TOPSIS method.

2.1. Construction of a Fuzzy Multicriterion Decision Matrix. Construction of fuzzy decision matrix is the first step for solving fuzzy multiattribute decision problems. Every alternative is evaluated under each criterion to obtain its performance measure. Suppose there are $k$ decision makers, $m$ alternatives, and $n$ criteria. Each decision maker $k$ can provide one fuzzy performance measure, $\tilde{x}_{i j}^{k}=\left(a_{i j}^{k}, m_{i j}^{k}, b_{i j}^{k}\right)$, under the $j$ th criterion for the $i$ th alternative, where $a_{i j}^{k}$ is smallest number, $m_{i j}^{k}$ is the medium number, and $b_{i j}^{k}$ is the largest number, that is, $a_{i j}^{k}<m_{i j}^{k}<b_{i j}^{k}$. The $k$ fuzzy performance measures are summed and denoted as $\tilde{x}_{i j}$ via (1). Then the fuzzy decision matrix $(\widetilde{D})$ can be constructed as shown in (2) as follows:

$$
\begin{gathered}
\tilde{x}_{i j}=\tilde{x}_{i j}^{1}+\tilde{x}_{i j}^{2}+\cdots+\tilde{x}_{i j}^{k} \\
\widetilde{D}=\left[\widetilde{x}_{i j}\right]_{m \times n}, \quad i=1,2, \ldots, m ; j=1,2, \ldots, n .
\end{gathered}
$$

2.2. Normalization of the Fuzzy Decision Matrix. In order to be comparable among each criterion, the collected data under different criteria should be normalized into the scale between 0 and 1 . At least two ways of normalization can be used in this purpose, that is, vector normalization and linear normalization [21-23]. The linear normalization is used in this study due to its simplicity. The normalized fuzzy decision matrix $\widetilde{R}$ can be obtained via (3) and (4), where $\widetilde{r}_{i j}$ is the normalized fuzzy number:

$$
\begin{gathered}
\widetilde{R}=\left[\widetilde{r}_{i j}\right]_{m \times n}, \quad i=1,2, \ldots, m ; j=1,2, \ldots, n, \\
\widetilde{r}_{i j}=\left(\frac{a_{i j}}{b_{j}^{+}}, \frac{m_{i j}}{b_{j}^{+}}, \frac{b_{i j}}{b_{j}^{+}}\right), \quad b_{j}^{+}=\max _{i}\left\{b_{i j}\right\},
\end{gathered}
$$

where $a_{i j}, m_{i j}$, and $b_{i j}$ are the smallest number, medium number, and the largest number, respectively, in the membership function $\tilde{x}_{i j}=\left(a_{i j}, m_{i j}, b_{i j}\right)$.

2.3. Calculation of Fuzzy Weights by Fuzzy Entropy Method. The entropy method provides a subjective way to estimate weight measure for each criterion [24]. In this study, the fuzzy entropy method is developed to assign fuzzy weight measures to criteria under consideration of fuzzy factors for the entropy method. First, the original fuzzy performance measures $\tilde{x}_{i j}$ are normalized as $\widetilde{r}_{i j}$ by (5), where $\tilde{x}_{j}^{*}$ is the largest measure number under the $j$ th criterion. In practice, $\tilde{x}_{j}^{*}$ can be replaced by $b_{j}^{+}$that appeared in (4). Next, the entropy measure for the $j$ th criterion, $\tilde{e}_{j}$, is calculated using (6), where $m$ is the number of alternatives. Then, the fuzzy weight for the $j$ th criterion, $\left(\widetilde{w}_{j}\right)$, is obtained by $(7)$ :

$$
\tilde{r}_{i j}=\frac{\tilde{x}_{i j}}{\tilde{x}_{j}^{*}}, \quad i=1,2, \ldots, m, j=1,2, \ldots, n,
$$




$$
\begin{aligned}
& \widetilde{e}_{j}=-\frac{1}{\ln m} \sum_{i=1}^{m} \widetilde{r}_{i j} \ln \widetilde{r}_{i j}, \quad j=1,2, \ldots, n, \\
& \widetilde{w}_{j}=\frac{1-\widetilde{e}_{j}}{\sum_{j=1}^{n}\left(1-\widetilde{e}_{j}\right)}, \quad j=1,2, \ldots, n .
\end{aligned}
$$

The intuitive meaning of (6) and (7) used to determine entropy and weights can be explained as follows. For an alternative, the larger is the contrast intensity of the $i$ th attribute, the greater is the amount of decision information contained in and transmitted by the attribute. Then we can use a fuzzy entropy measure to show the average intrinsic information transmitted to the decision maker through the $i$ th attribute by the definition of attribute importance. The fuzzy entropy measure of the $i$ th attribute contrast intensity can be defined by (6). Hence, for the $i$ th attribute, the larger the fuzzy entropy measure is, the less information is transmitted by the $i$ th attribute. Then, a normalized fuzzy weight can be defined by (7).

2.4. Weighting of the Normalized Fuzzy Decision Matrix. Since each criterion can have different preferences, the obtained fuzzy weight measures are used to reflect such facts by multiplying into the normalized decision matrix, as shown in (8), where the notation $\odot$ denotes multiplication operations, $\widetilde{v}_{i j}$ is the weighted fuzzy number, and $\widetilde{V}$ represents the weighted decision matrix as follows:

$$
\begin{array}{ll}
\widetilde{v}_{i j}=\widetilde{r}_{i j} \odot w_{j}, & i=1,2, \ldots, m ; j=1,2, \ldots, n \\
\widetilde{V} & =\left[\widetilde{v}_{i j}\right]_{m \times n}, \quad i=1,2, \ldots, m ; j=1,2, \ldots, n .
\end{array}
$$

2.5. Numbering and Attributing. One metric used in the fuzzy TOPSIS method to assess alternatives is based on the measure of distance to positive and negative ideal solutions, respectively. The determination of positive and negative ideal solutions may consider three situations regarding the characteristics of quality responses, that is, the larger the better, the smaller the better, and the nominal the better. To determine the fuzzy positive ideal solution $\left(\widetilde{A}^{+}\right),(9)$ is used for the response with the larger the better, (10) for the response with the smaller the better, and (11) for the response with the nominal the better, respectively, where $J_{1}$ is a set of benefit attributes, $J_{2}$ is a set of cost attributes, and $\widetilde{v}^{*}$ is the weighted normalized fuzzy target value:

$$
\begin{aligned}
\widetilde{A}^{+}= & \left(\widetilde{v}_{1}^{+}, \widetilde{v}_{2}^{+}, \ldots, \widetilde{v}_{j}^{+}, \ldots, \widetilde{v}_{n}^{+}\right) \\
= & \left\{\left(\max \widetilde{v}_{i j} \mid j \in J_{1}\right) \mid i=1, \ldots, m\right\}, \\
\widetilde{A}^{+}= & \left(\widetilde{v}_{1}^{+}, \widetilde{v}_{2}^{+}, \ldots, \widetilde{v}_{j}^{+}, \ldots, \widetilde{v}_{n}^{+}\right) \\
= & \left\{\left(\max \widetilde{v}_{i j} \mid j \in J_{1}\right) \mid i=1, \ldots, m\right\}, \\
& \widetilde{A}^{+}=\left(\widetilde{v}_{1}^{+}, \widetilde{v}_{2}^{+}, \ldots, \widetilde{v}_{j}^{+}, \ldots, \widetilde{v}_{n}^{+}\right),
\end{aligned}
$$

where $\widetilde{v}_{j}^{+}=$target value of $\left\{\widetilde{v}_{i j}\right\}=\widetilde{v}^{*}$.

Similarly, to determine the fuzzy negative ideal solution $\left(\widetilde{A}^{-}\right),(12)$ is used for the response with the larger the better,
(13) for the response with the smaller the better, and (14) for the response with the nominal the better, respectively:

$$
\begin{aligned}
\widetilde{A}^{-}= & \left(\widetilde{v}_{1}^{-}, \widetilde{v}_{2}^{-}, \ldots, \widetilde{v}_{j}^{-}, \ldots, \widetilde{v}_{n}^{-}\right) \\
= & \left\{\left(\min \widetilde{v}_{i j} \mid j \in J_{1}\right) \mid i=1, \ldots, m\right\}, \\
\widetilde{A}^{-}= & \left(\widetilde{v}_{1}^{-}, \widetilde{v}_{2}^{-}, \ldots, \widetilde{v}_{j}^{-}, \ldots, \widetilde{v}_{n}^{-}\right) \\
= & \left\{\left(\max \widetilde{v}_{i j} \mid j \in J_{2}\right) \mid i=1, \ldots, m\right\}, \\
& \widetilde{A}^{-}=\left(\widetilde{v}_{1}^{-}, \widetilde{v}_{2}^{-}, \ldots, \widetilde{v}_{j}^{-}, \ldots, \widetilde{v}_{n}^{-}\right),
\end{aligned}
$$

where

$$
\widetilde{v}_{j}^{-}= \begin{cases}\min _{i}\left\{\widetilde{v}_{i j}\right\}, & \text { if } \widetilde{v}_{i j}<\widetilde{v}^{*} \\ \max _{i}\left\{\widetilde{v}_{i j}\right\}, & \text { if } \widetilde{v}_{i j}>\widetilde{v}^{*}\end{cases}
$$

2.6. Calculation of the Distances to Fuzzy Positive and Negative Ideal Solutions. Let $\widetilde{d}_{i}^{+}$be the distance to the fuzzy positive ideal solution from alternative $i$ and let $\tilde{d}_{i}^{-}$be the distance to the fuzzy negative ideal solution from alternative $i$. Then (16) can be used to calculate for $\widetilde{d}_{i}^{+}$and $\tilde{d}_{i}^{-}$as follows:

$$
\begin{aligned}
& \tilde{d}_{i}^{+}=\sqrt{\sum_{i=1}^{n}\left(\widetilde{v}_{i j}-\widetilde{v}_{j}^{+}\right)^{2}}, \quad i=1,2, \ldots, n, \\
& \tilde{d}_{i}^{-}=\sqrt{\sum_{i=1}^{n}\left(\tilde{v}_{i j}-\tilde{v}_{j}^{-}\right)^{2}}, \quad i=1,2, \ldots, n .
\end{aligned}
$$

2.7. Computation of the Fuzzy Relative Closeness for Each Alternative. Let $\widetilde{C}_{i}$ be the fuzzy relative closeness coefficient for alternative $i$. Equation (17) can be used to compute the fuzzy relative closeness coefficient. The fuzzy relative closeness for alternative $i$ represents the degree of proximity to the positive ideal solution. If the computed $\widetilde{C}_{i}$ value is close to 1 , one can infer that alternative $i$ approaches the positive ideal solution and it could be the best one among other alternatives. Otherwise, if $\widetilde{C}_{i}$ value is far less than 1 , alternative $i$ will not be a good one:

$$
\widetilde{C}_{i}=\frac{\widetilde{d}_{j}^{-}}{\widetilde{d}_{j}^{+}+\widetilde{d}_{j}^{-}}, \quad 0 \leq \widetilde{C}_{i} \leq 1 .
$$

2.8. Ranking of the Alternatives by the Fuzzy Closeness Coefficient. The obtained fuzzy closeness coefficients are averaged and used to rank all possible alternatives. The larger the mode of $\widetilde{C}_{i}$ is, the better the alternative $i$ will be.

\section{A Case Study}

In this study, one of the wafer fabrication processes, the deposition process, is used as a case study for showing the implementation of the developed fuzzy TOPSIS method. 
TABLE 1: $L_{18}\left(2^{1} \times 3^{2}\right)$ orthogonal table for control factors and levels.

\begin{tabular}{|c|c|c|c|c|c|c|}
\hline Number & (A) Temperature & (B) Pressure & (C) Nitrogen flow & (D) Silane flow & (E) Setup time & (F) Cleaning method \\
\hline 1 & $T_{0}-25$ & $P_{0}-200$ & $N_{0}$ & $S_{0}-100$ & $t_{0}$ & None \\
\hline 2 & $T_{0}-25$ & $P_{0}$ & $N_{0}-150$ & $S_{0}-50$ & $t_{0}+8$ & $\mathrm{CM}_{2}$ \\
\hline 3 & $T_{0}-25$ & $P_{0}+200$ & $N_{0}-75$ & $S_{0}$ & $t_{0}+16$ & $\mathrm{CM}_{3}$ \\
\hline 4 & $T_{0}$ & $P_{0}-200$ & $N_{0}$ & $S_{0}-50$ & $t_{0}+8$ & $\mathrm{CM}_{3}$ \\
\hline 5 & $T_{0}$ & $P_{0}$ & $N_{0}-150$ & $S_{0}$ & $t_{0}+16$ & None \\
\hline 6 & $T_{0}$ & $P_{0}+200$ & $N_{0}-75$ & $S_{0}-100$ & $t_{0}$ & $\mathrm{CM}_{2}$ \\
\hline 7 & $T_{0}+25$ & $P_{0}-200$ & $N_{0}-150$ & $S_{0}-100$ & $t_{0}+16$ & $\mathrm{CM}_{3}$ \\
\hline 8 & $T_{0}+25$ & $P_{0}$ & $N_{0}-75$ & $S_{0}-50$ & $t_{0}$ & None \\
\hline 9 & $T_{0}+25$ & $P_{0}+200$ & $N_{0}$ & $S_{0}$ & $t_{0}+8$ & $\mathrm{CM}_{2}$ \\
\hline 10 & $T_{0}-25$ & $P_{0}-200$ & $N_{0}-75$ & $S_{0}$ & $t_{0}+8$ & None \\
\hline 11 & $T_{0}-25$ & $P_{0}$ & $N_{0}$ & $S_{0}-100$ & $t_{0}+16$ & $\mathrm{CM}_{2}$ \\
\hline 12 & $T_{0}-25$ & $P_{0}+200$ & $N_{0}-150$ & $S_{0}-50$ & $t_{0}$ & $\mathrm{CM}_{3}$ \\
\hline 13 & $T_{0}$ & $P_{0}-200$ & $N_{0}-150$ & $S_{0}$ & $t_{0}$ & $\mathrm{CM}_{2}$ \\
\hline 14 & $T_{0}$ & $P_{0}$ & $N_{0}-75$ & $S_{0}-100$ & $t_{0}+8$ & $\mathrm{CM}_{3}$ \\
\hline 15 & $T_{0}$ & $P_{0}+200$ & $N_{0}$ & $S_{0}-50$ & $t_{0}+16$ & None \\
\hline 16 & $T_{0}+25$ & $P_{0}-200$ & $N_{0}-75$ & $S_{0}-50$ & $t_{0}+16$ & $\mathrm{CM}_{2}$ \\
\hline 17 & $T_{0}+25$ & $P_{0}$ & $N_{0}$ & $S_{0}$ & $t_{0}$ & $\mathrm{CM}_{3}$ \\
\hline 18 & $T_{0}+25$ & $P_{0}+200$ & $N_{0}-150$ & $S_{0}-100$ & $t_{0}+8$ & None \\
\hline
\end{tabular}

TABLE 2: Fuzzy weights for each quality response.

\begin{tabular}{lc}
\hline Response & Fuzzy weight \\
\hline Defect number & $\widetilde{w}_{1}=(0.8286,0.8052,0.8081)$ \\
Density & $\widetilde{w}_{2}=(0.0460,0.0520,0.0511)$ \\
Deposition rate & $\widetilde{w}_{3}=(0.1254,0.1428,0.1408)$ \\
\hline
\end{tabular}

During the deposition process, three quality responses place significant effects on the quality of wafers, that is, defect number on wafer surface, density of wafer, and deposition rate. The defect number is the type of the-smaller-the-better response, the density of the-larger-the-better response, and the deposition rate of the-nominal-the-better response.

During the experiment, six control factors are selected, that is, deposition temperature, deposition pressure, nitrogen flow, silane flow, setup time, and cleaning method. Each control factor has three levels. By the Taguchi experimental design method, the $L_{18}\left(2^{1} \times 3^{2}\right)$ orthogonal table is used to provide eighteen combinations for this experiment, shown in Table 1.

For each combination of experiment, three wafers were randomly selected from one batch of 50 wafers and were inspected in terms of defect number, density, and deposition rate on three positions of each wafer, that is, top, central, and bottom. Experimental data were collected and summarized to provide a fuzzy decision matrix. The obtained fuzzy decision matrix is normalized. The fuzzy entropy method is then applied to estimate fuzzy weights for each quality response, provided in Table 2 . Using the fuzzy weights, the weighted fuzzy decision matrix is calculated in Table 3.

The fuzzy positive and negative ideal solutions for each quality response are computed and shown in Table 4 . Then, the distances to the fuzzy positive and negative ideal solutions for each combination are obtained. The relative closeness coefficients are calculated. Finally, the calculated relative closeness coefficients are averaged over each level of control factors in Table 5 and the best combination of control factors can be found in Table 6 .

\section{Conclusions}

The quality problems arising in the IC semiconductor components are diverse, variable, and fuzzy. The design of wafer fabrication process should consider many aspects of the quality problem because it takes so much time and cost to solve the quality problem. A fuzzy TOPSIS method with fuzzy entropy weight measure is developed for the fuzzy multiresponse quality problem. Since during the deposition process in wafer fabrication, some undesired defect number on the wafer surface might occur quite often and the variability of the density within wafers and in-between wafers might be large, it is essential to investigate those causes and effects to improve the quality problem. In this study, the deposition process in the wafer fabrication is used as a case study to demonstrate the merit of the developed fuzzy TOPSIS method. Results of this study indicate that the developed approach provides a satisfactory combination of control factors for the wafer fabrication process.

There are several opportunities that can apply the developed fuzzy TOPSIS approach for future study. One can find that the demand for electronic product with higher quality is increasing and the environment under the various quality measurements is becoming uncertain and fuzzy. The developed fuzzy TOPSIS method can be applied for those manufacturing processes to solving multiresponse quality 
TABLE 3: Weighted fuzzy decision matrix.

\begin{tabular}{lccc}
\hline Number & Defect number $\left(\widetilde{v}_{i 1}\right)$ & Density $\left(\widetilde{v}_{i 2}\right)$ & Deposition rate $\left(\widetilde{v}_{i 3}\right)$ \\
\hline 1 & $(0.0000,0.0000,0.0002)$ & $(0.0147,0.0167,0.0167)$ & $(0.0156,0.0179,0.0180)$ \\
2 & $(0.0004,0.0004,0.0138)$ & $(0.0395,0.0449,0.0446)$ & $(0.0395,0.0453,0.0451)$ \\
3 & $(0.0057,0.0188,0.0304)$ & $(0.0448,0.0506,0.0511)$ & $(0.0446,0.0509,0.0515)$ \\
4 & $(0.0017,0.0018,0.0034)$ & $(0.0160,0.0182,0.0180)$ & $(0.0390,0.0447,0.0444)$ \\
5 & $(0.1111,0.1409,0.1898)$ & $(0.0346,0.0391,0.0386)$ & $(0.0793,0.0903,0.0895)$ \\
6 & $(0.0385,0.0741,0.2274)$ & $(0.0217,0.0247,0.0247)$ & $(0.0533,0.0611,0.0613)$ \\
7 & $(0.0718,0.0737,0.1697)$ & $(0.0254,0.0288,0.0287)$ & $(0.0827,0.0947,0.0945)$ \\
8 & $(0.1361,0.2238,0.4772)$ & $(0.0329,0.0386,0.0398)$ & $(0.1100,0.1300,0.1345)$ \\
9 & $(0.1841,0.2147,0.4938)$ & $(0.0298,0.0338,0.0333)$ & $(0.1249,0.1425,0.1408)$ \\
10 & $(0.0000,0.0000,0.0003)$ & $(0.0258,0.0292,0.0289)$ & $(0.0269,0.0307,0.0304)$ \\
11 & $(0.0000,0.0001,0.0003)$ & $(0.0191,0.0217,0.0215)$ & $(0.0217,0.0247,0.0246)$ \\
12 & $(0.0045,0.0219,0.0733)$ & $(0.0435,0.0496,0.0488)$ & $(0.0422,0.0484,0.0478)$ \\
13 & $(0.0020,0.0121,0.0465)$ & $(0.0204,0.0233,0.0231)$ & $(0.0573,0.0658,0.0654)$ \\
14 & $(0.0019,0.0070,0.0091)$ & $(0.0216,0.0244,0.0241)$ & $(0.0496,0.0565,0.0560)$ \\
15 & $(0.1593,0.1747,0.2186)$ & $(0.0241,0.0272,0.0273)$ & $(0.0593,0.0675,0.0678)$ \\
16 & $(0.0003,0.0022,0.0033)$ & $(0.0235,0.0266,0.0262)$ & $(0.0834,0.0952,0.0939)$ \\
17 & $(0.1615,0.1836,0.5477)$ & $(0.0298,0.0346,0.0358)$ & $(0.1105,0.1294,0.1343)$ \\
18 & $(0.2532,0.2908,0.8081)$ & $(0.0272,0.0308,0.0303)$ & $(0.0993,0.1132,0.1119)$ \\
\hline
\end{tabular}

TABLE 4: Positive and negative ideal solutions for each quality response.

\begin{tabular}{lcc}
\hline Quality response & Positive ideal solution $\left(\widetilde{A}^{+}\right)$ & Negative ideal solution $\left(\widetilde{A}^{-}\right)$ \\
\hline $\begin{array}{l}\text { Deposition rate } \\
\text { Defect number }\end{array}$ & $\widetilde{A}^{+}=(0.1249,0.1425,0.1408)$ & $\widetilde{A}^{-}=(0.0156,0.0179,0.0180)$ \\
Density & $\widetilde{A}^{+}=(0.0000,0.0000,0.0002)$ & $\widetilde{A}^{-}=(0.2532,0.2908,0.8081)$ \\
& $\widetilde{A}^{+}=(0.0273,0.0308,0.0303)$ & $\widetilde{A}^{-}=(0.0448,0.0506,0.0511)$, if $\widetilde{v}_{i 2}>(0.0273,0.0308,0.0303)$ \\
& & $\widetilde{A}^{-}=(0.0147,0.0167,0.0167)$, if $\widetilde{v}_{i 2}<(0.0273,0.0308,0.0303)$ \\
\hline
\end{tabular}

TABLE 5: Closeness coefficients for each combination of control factors.

\begin{tabular}{|c|c|c|c|c|c|c|c|c|}
\hline Number & $\mathrm{A}$ & $\mathrm{B}$ & $\mathrm{C}$ & $\mathrm{D}$ & $\mathrm{E}$ & $\mathrm{F}$ & $\widetilde{C}_{i}$ & $\mathrm{~m}\left(\widetilde{C}_{i}\right)$ \\
\hline 1 & 1 & 1 & 1 & 1 & 1 & 1 & $(0.6972,0.6987,0.8673)$ & 0.6987 \\
\hline 2 & 1 & 2 & 2 & 2 & 2 & 2 & $(0.7466,0.7481,0.8905)$ & 0.7481 \\
\hline 3 & 1 & 3 & 3 & 3 & 3 & 3 & $(0.7517,0.7413,0.8896)$ & 0.7413 \\
\hline 4 & 2 & 1 & 1 & 2 & 2 & 3 & $(0.7446,0.7465,0.8923)$ & 0.7465 \\
\hline 5 & 2 & 2 & 2 & 3 & 3 & 1 & $(0.5647,0.5258,0.7600)$ & 0.5258 \\
\hline 6 & 2 & 3 & 3 & 1 & 1 & 2 & $(0.7280,0.6673,0.7075)$ & 0.6673 \\
\hline 7 & 3 & 1 & 2 & 1 & 3 & 3 & $(0.6993,0.7242,0.7854)$ & 0.7242 \\
\hline 8 & 3 & 2 & 3 & 2 & 1 & 1 & $(0.5241,0.3691,0.4239)$ & 0.3691 \\
\hline 9 & 3 & 3 & 1 & 3 & 2 & 2 & $(0.4140,0.4063,0.4063)$ & 0.4063 \\
\hline 10 & 1 & 1 & 3 & 3 & 2 & 1 & $(0.7213,0.7227,0.8798)$ & 0.7227 \\
\hline 11 & 1 & 2 & 1 & 1 & 3 & 2 & $(0.7099,0.7112,0.8739)$ & 0.7112 \\
\hline 12 & 1 & 3 & 2 & 2 & 1 & 3 & $(0.7478,0.7334,0.8600)$ & 0.7334 \\
\hline 13 & 2 & 1 & 2 & 3 & 1 & 2 & $(0.7893,0.7839,0.8958)$ & 0.7839 \\
\hline 14 & 2 & 2 & 3 & 1 & 2 & 3 & $(0.7707,0.7682,0.9035)$ & 0.7682 \\
\hline 15 & 2 & 3 & 1 & 2 & 3 & 1 & $(0.3764,0.3999,0.7198)$ & 0.3999 \\
\hline 16 & 3 & 1 & 3 & 2 & 3 & 2 & $(0.8629,0.8629,0.9449)$ & 0.8629 \\
\hline 17 & 3 & 2 & 1 & 3 & 1 & 3 & $(0.4501,0.4581,0.3428)$ & 0.4581 \\
\hline 18 & 3 & 3 & 2 & 1 & 2 & 1 & $(0.2495,0.2479,0.1063)$ & 0.2479 \\
\hline
\end{tabular}


TABLE 6: Averaged closeness value over each level of control factors.

\begin{tabular}{lcccccc}
\hline Level & $\mathrm{A}$ & $\mathrm{B}$ & $\mathrm{C}$ & $\mathrm{D}$ & $\mathrm{E}$ & $\mathrm{F}$ \\
\hline 1 & $\mathbf{0 . 7 2 5 9}$ & $\mathbf{0 . 7 5 6 5}$ & 0.5701 & 0.6363 & 0.6184 & 0.4940 \\
2 & 0.6486 & 0.5967 & 0.6272 & $\mathbf{0 . 6 4 3 3}$ & 0.6066 & $\mathbf{0 . 6 9 6 6}$ \\
3 & 0.5114 & 0.5327 & $\mathbf{0 . 6 8 8 6}$ & 0.6063 & $\mathbf{0 . 6 6 0 9}$ & 0.6953 \\
\hline Best combination & & \multicolumn{5}{c}{$\mathrm{A}_{1} \mathrm{~B}_{1} \mathrm{C}_{3} \mathrm{D}_{2} \mathrm{E}_{3} \mathrm{~F}_{2}$} \\
\hline
\end{tabular}

problems under uncertain environments. Also, one can investigate the possible benefits for applying different fuzzy MADA methods for solving the multiresponse quality problems.

\section{References}

[1] M. S. Phadke, Quality Engineering Using Robust Design, Prentice-Hall, Englewood Cliffs, NJ, USA, 1989.

[2] J. Antony, "Simultaneous optimisation of multiple quality characteristics in manufacturing processes using Taguchi's quality loss function," International Journal of Advanced Manufacturing Technology, vol. 17, no. 2, pp. 134-138, 2001.

[3] R. M. Dabbas, J. W. Fowler, D. A. Rollier, and D. McCarville, "Multiple response optimization using mixture-designed experiments and desirability functions in semiconductor scheduling," International Journal of Production Research, vol. 41, no. 5, pp. 939-961, 2003.

[4] J. L. Lin, K. S. Wang, B. H. Yan, and Y. S. Tarng, "Optimization of the electrical discharge machining process based on the Taguchi method with fuzzy logics," Journal of Materials Processing Technology, vol. 102, no. 1, pp. 48-55, 2000.

[5] P. B. S. Reddy, K. Nishina, and A. Subash Babu, "Unification of robust design and goal programming for multiresponse optimization-a case study," Quality and Reliability Engineering International, vol. 13, no. 6, pp. 371-383, 1997.

[6] Y. M. Chiang and H. H. Hsieh, "The use of the Taguchi method with grey relational analysis to optimize the thin-film sputtering process with multiple quality characteristic in color filter manufacturing," Computers and Industrial Engineering, vol. 56, no. 2, pp. 648-661, 2009.

[7] C. P. Fung and P. C. Kang, "Multi-response optimization in friction properties of PBT composites using Taguchi method and principle component analysis," Journal of Materials Processing Technology, vol. 170, no. 3, pp. 602-610, 2005.

[8] T. Goel, R. Vaidyanathan, R. T. Haftka, W. Shyy, N. V. Queipo, and K. Tucker, "Response surface approximation of Pareto optimal front in multi-objective optimization," Computer Methods in Applied Mechanics and Engineering, vol. 196, no. 4-6, pp. 879893, 2007.

[9] T. H. Hou, C. H. Su, and H. Z. Chang, "Using neural networks and immune algorithms to find the optimal parameters for an IC wire bonding process," Expert Systems with Applications, vol. 34, no. 1, pp. 427-436, 2008.

[10] K. L. Hsieh, L. L. Tong, H. P. Chiu, and H. Y. Yeh, "Optimization of a multi-response problem in Taguchi's dynamic systems," Computers and Industrial Engineering, vol. 49, pp. 556-571, 2005.

[11] K. L. Hsieh and L. I. Tong, "Optimization of multiple quality responses involving qualitative and quantitative characteristics in IC manufacturing using neural networks," Computers in Industry, vol. 46, no. 1, pp. 1-12, 2001.
[12] O. Köksoy, "A nonlinear programming solution to robust multiresponse quality problem," Applied Mathematics and Computation, vol. 196, no. 2, pp. 603-612, 2008.

[13] T. S. Li, C. T. Su, and T. L. Chiang, "Applying robust multiresponse quality engineering for parameter selection using a novel neural-genetic algorithm," Computers in Industry, vol. 50, no. 1, pp. 113-122, 2003.

[14] H. C. Liao, "A data envelopment analysis method for optimizing multi-response problem with censored data in the Taguchi method," Computers and Industrial Engineering, vol. 46, no. 4, pp. 817-835, 2004.

[15] W. Baran, "Development of design methods for permanent magnet circuits, demonstrated with a core magnet assembly," Journal of Magnetism and Magnetic Materials, vol. 19, no. 1-3, pp. 326-328, 1980.

[16] O. L. Chau and C. Parkan, "Selection of a manufacturing process with multiple attributes: a case study," Journal of Engineering and Technology Management, vol. 12, no. 3, pp. 219-237, 1995.

[17] W. R. Greiff, "Soft computing in information retrieval: techniques and applications," Inforamtion Processing and Management, vol. 39, pp. 329-330, 2003.

[18] C. L. Hwang and K. Yoon, Multiple Attribute Decision Making Methods and Applications, Springer, Berlin, Germany, 1981.

[19] R. A. Ribeiro, "Fuzzy multiple attribute decision making: a review and new preference elicitation techniques," Fuzzy Sets and Systems, vol. 78, no. 2, pp. 155-181, 1996.

[20] M. Zelany, "A concept of compromise solutions and the method of the displaced ideal," Computers and Operations Research, vol. 1, no. 3-4, pp. 479-496, 1974.

[21] T. C. Chu and Y. C. Lin, "A fuzzy TOPSIS method for robot selection," International Journal of Advanced Manufacturing Technology, vol. 21, no. 4, pp. 284-290, 2003.

[22] E. Bottani and A. Rizzi, "A fuzzy TOPSIS methodology to support outsourcing of logistics services," Supply Chain Management, vol. 11, no. 4, pp. 294-308, 2006.

[23] T. C. Wang and T. H. Chang, "Application of TOPSIS in evaluating initial training aircraft under a fuzzy environment," Expert Systems with Applications, vol. 33, no. 4, pp. 870-880, 2007.

[24] Z. H. Zou, Y. Yun, and J. N. Sun, "Entropy method for determination of weight of evaluating indicators in fuzzy synthetic evaluation for water quality assessment," Journal of Environmental Sciences, vol. 18, no. 5, pp. 1020-1023, 2006. 

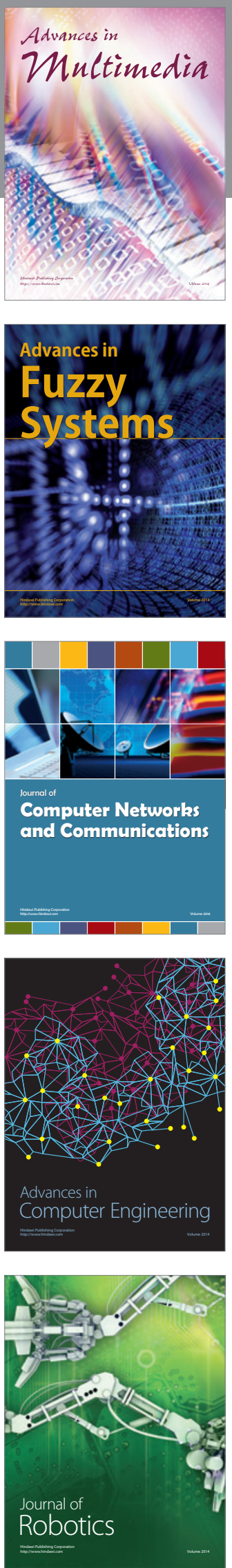

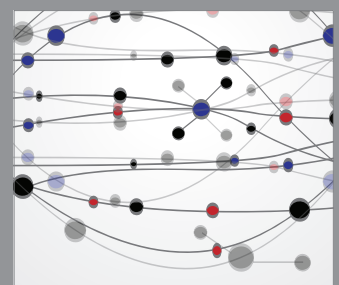

The Scientific World Journal
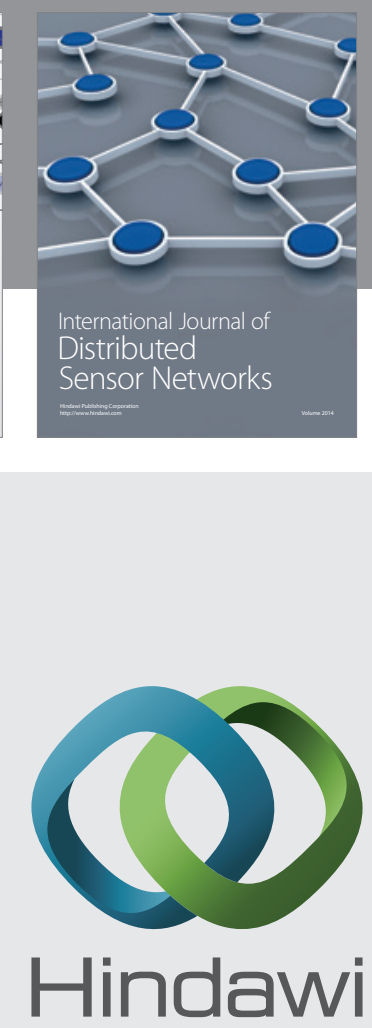

Submit your manuscripts at

http://www.hindawi.com
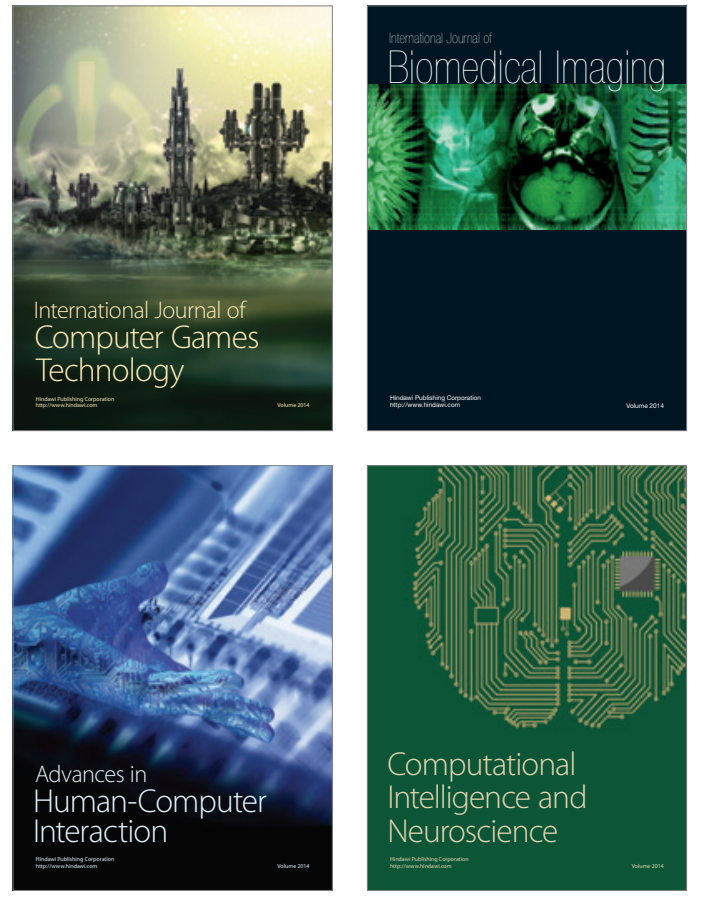
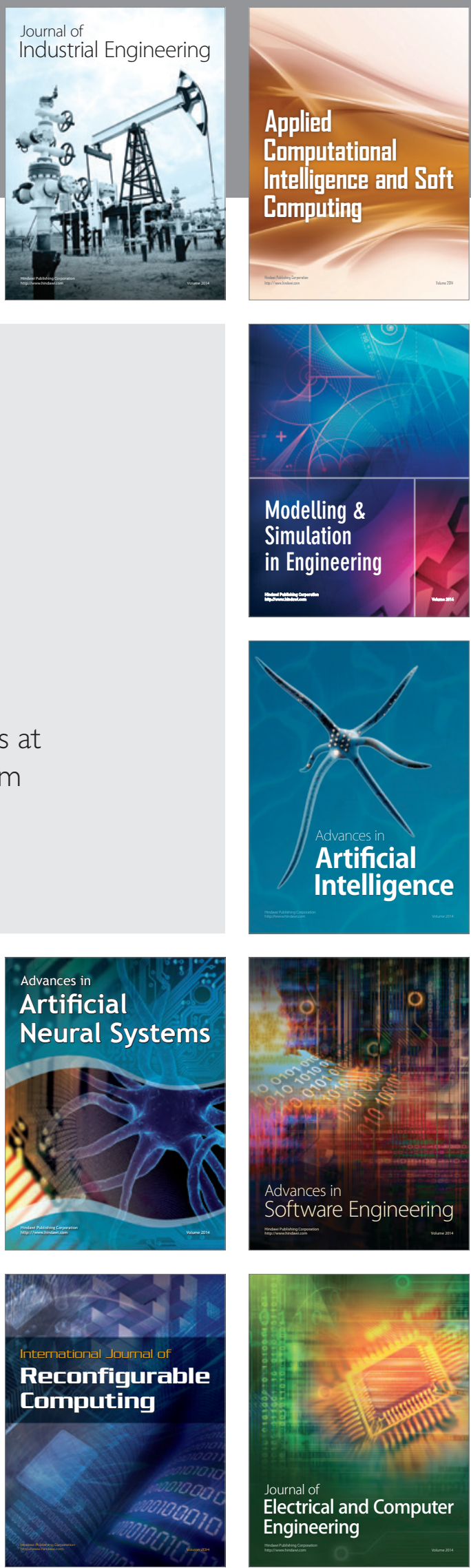